\title{
Treatment Patterns and Characteristics of Individuals Initiating High-Dose Insulin for Type 2 Diabetes Mellitus
}

\author{
Jieling Chen, PhD; Radhika Nair, PhD; Mir Siadaty, MD, MS; Katelyn Brown, PharmD, RPh; \\ Yunus Meah, PharmD; April Dawn Taylor, MSN, CNS, BC-ADM; Xuanyao He, PhD; and Ludi Fan, PhD
}

\begin{abstract}
BACKGROUND: Few studies have examined patient characteristics and treatment patterns of high-dose insulin therapy (> 200 units/day) among patients with type 2 diabetes mellitus (T2DM).

OBJECTIVE: To understand patient characteristics, dosing, adherence, and persistence related to high-dose insulin therapy.

METHODS: This was a retrospective observational study that used administrative claims from a large national health plan. Patients were identified who had been diagnosed with T2DM and who were aged 18-89 years, enrolled in a commercial or Medicare Advantage Prescription Drug plan, newly initiated on a total daily dose (TDD) $>200$ units of insulin between January 2011 and August 2015. Patients were required to be enrolled 6 months before and 12 months after the index date. Patients were categorized to Regimen-100 if treated with U-100 insulin only or Regimen-500 if treated with U-500R with or without U-100. Baseline demographic and clinical characteristics were evaluated. An adjustment factor for the days supply was calculated as the ratio of median time between insulin claims, and median pharmacy reported days supply for each insulin prescription. Adjusted days supply, quantity, and concentration were used to calculate TDD for each quarter after the index date.

Adherence was measured as the proportion of days covered (PDC) for each regimen. Persistence was measured in 2 ways: the percentage of patients remaining on index medications in each quarter and the proportion of patients who maintained TDD $>200$ units during all 4 quarters of the 12-month post-index period.
\end{abstract}

RESULTS: We identified 2,339 patients newly titrated up to TDD $>200$ units on either Regimen-100 (2,062, 88.2\%) or Regimen-500 (277, 11.8\%). Patients on Regimen-500 were slightly younger with higher prevalence of comorbidities. The mean TDD (SD) for Regimen-100 decreased from 228.6 (36.0) units during the first quarter to 194.2 (181.4) units during the last quarter. The mean TDD (SD) for Regimen-500 increased from 294.2 (102.2) units in the first quarter to 304.8 (281.6) units in last quarter. The average adherence to the high-dose insulin regimen was $68.2 \%(30.7$; median $72.6 \%$ ) for the Regimen-100 cohort and $75.5 \%$ (27.0; median $85.2 \%$ ) for the Regimen-500 cohort. In the Regimen-100 and Regimen-500 cohorts, $45.3 \%$ and $55.2 \%$ had a PDC $\geq 80 \%$, respectively. Only $23.0 \%$ and $51.6 \%$ of patients maintained TDD $>200$ units for the Regimen-100 and Regimen-500 cohorts, respectively, throughout the 4 quarters after the index date.

CONCLUSIONS: We observed that many patients did not maintain high-dose insulin use over time, especially those on standard U-100 insulin only. This dosing pattern appears to reflect the differences in patient characteristics, insulin needs, and adherence/persistence behavior between those on Regimen-100 and those on Regimen-500.

J Manag Care Spec Pharm. 2020;26(7):839-47

Copyright $\odot 2020$, Academy of Managed Care Pharmacy. All rights reserved.

\section{What is already known about this subject}

Previous studies of patients on high-dose insulin have not differentiated between type 1 and type 2 diabetes mellitus (T1DM and T2DM) populations.

In patients with T1DM or T2DM, adherence to a high-dose regimen ( $\geq 150$ units/day or $>200$ units/day) was greater with U-500R insulin than with U-100 insulin.

\section{What this study adds}

Patients with T2DM initiating high-dose insulin therapy (total daily dose $>200$ units) with Regimen-500 were slightly younger and had greater prevalence of diabetes-related comorbidities compared with those initiating high-dose therapy with Regimen-100.

Adherence to therapy (proportion of days covered $\geq 80 \%$ ) for the population in this study (slightly older, higher number of Medicare Advantage and Prescription Drug plans, and enrollees diagnosed with T2DM) in both Regimen-100 (45.3\%) and Regimen-500 cohorts (55.2\%) was higher than has been previously reported. A total of $51.6 \%$ and $23.0 \%$ of patients in the Regimen-500 and Regimen-100 cohorts, respectively, maintained high-dose insulin for an entire year; the dose for Regimen-100 decreased over time, but not for Regimen-500.

A long with the rising prevalence of obesity and type 2 diabetes mellitus (T2DM) in the United States, ${ }^{1,2}$ there is a rising prevalence of patients with severe insulin resistance, which has been historically defined as a total daily insulin requirement of $>200$ units per day or $>2$ units per $\mathrm{kg}$ per day (units/kg/day). ${ }^{3,4}$ Basal and bolus insulins of standard concentration (U-100) delivered by multiple injections daily are the most commonly used treatment regimens to achieve glycemic control. ${ }^{5-7}$ In recent years, concentrated insulins (insulin glargine 300 units/mL [U-300], insulin lispro 200 units/mL [U-200], insulin degludec 200 units/mL [U-200], and concentrated human regular U-500 insulin [U-500R]) have offered options that may reduce the injection volume and number of injections for patients.

Patient adherence and persistence to therapy are important for those diagnosed with T2DM to achieve glycemic control and improve outcomes. ${ }^{8-10}$ Adherence is defined as "a patient 
taking the medication in accordance with the prescribed interval and dose of a dosing regimen," and persistence refers to "a patient continuing treatment for prescribed duration." Unlike oral medications, insulin can have non-fixed dosing schedules, which makes calculation of adherence challenging. A high-dose insulin regimen may require multiple injections, which can hinder adherence. ${ }^{12}$ While there are several claimsbased, retrospective observational studies on adherence and persistence to antidiabetic medications, ${ }^{9,10,13-17}$ fewer studies have focused on high-dose, standard, or concentrated insulin regimens. ${ }^{18-21}$ Some studies suggest that there may be improved glycemic control, ${ }^{18}$ adherence, ${ }^{21}$ and lower costs among patients using concentrated U-500R insulin compared with those patients using U-100 insulin. ${ }^{20,21}$ These studies did not differentiate between patients with type 1 diabetes mellitus (T1DM) or T2DM, and calculated dosing mainly for U-100 insulin.

To address this gap in the literature, the objective of this study was to evaluate the characteristics of patients with T2DM initiating high-dose insulin (>200 units/day) regimens and to describe the dosing, adherence, and persistence to these insulin regimens.

\section{Methods}

This was a retrospective observational study using administrative claims data from a large national health plan. High-dose insulin, for the purposes of this study, was defined as a total daily dose (TDD) $>200$ units. Patients identified for this study were aged between 19 and 89 years, with at least 2 medical claims with a diagnosis for T2DM using International Classification of Diseases, Ninth Revision, Clinical Modification codes between January 1, 2011, and August 31, 2015, and had at least 1 prescription claim for U-100, U-200, U-300, or U-500R insulin formulations. The fill date of the first claim associated with TDD $>200$ units was defined as the index date. Both of the following conditions needed to be satisfied for the date of the prescription claim to be defined as the index date: (1) TDD > 200 units for an entire 91-day window and (2) at least 31 days of TDD > 200 in the first 61 days of the 91-day window. The post-index period (12 months) was divided into quarters, and the insulins identified within the first quarter were defined as index medications and assigned to a regimen.

Patients were required to be continuously enrolled in a commercial or Medicare Advantage Prescription Drug (MAPD) plan with medical and pharmacy benefits for 6 months before and 1 year after the index date. High-dose insulin initiators included patients with insulin TDD $\leq 200$ units during the preindex period. Patients with a diagnosis for secondary diabetes, gestational diabetes, neonatal diabetes mellitus, or nonclinical diabetes during the pre- or post-index periods were excluded. Patients with insulin TDD $>2,500$ units or with claims for an

\begin{tabular}{|c|c|c|}
\hline Category & Number of Claims & Adjustment Factor \\
\hline Intermediate small vial & 528 & 1.1667 \\
\hline Intermediate pen & 8,382 & 1.6000 \\
\hline Intermediate vial & 139,634 & 1.2333 \\
\hline Insulin degludec & 1,417 & 1.1667 \\
\hline Insulin glargine 300 & 9,099 & 1.2000 \\
\hline Insulin detemir pen & 203,937 & 1.5333 \\
\hline Insulin detemir vial & 87,208 & 1.1667 \\
\hline Insulin glargine pen & 500,970 & 1.6333 \\
\hline Insulin glargine vial & 512,831 & 1.2000 \\
\hline Mix pen & 121,192 & 1.3000 \\
\hline Mix vial & 326,853 & 1.1667 \\
\hline Rapid acting pen & 254,273 & 1.6000 \\
\hline Rapid acting vial & 212,708 & 1.2000 \\
\hline Regular pen & $<10$ & 1.1765 \\
\hline Regular small vial & 1,819 & 2.3000 \\
\hline Regular vial & 82,793 & 1.2333 \\
\hline U-500R pen & 39 & 0.8667 \\
\hline U-500R vial & 6,737 & 1.4333 \\
\hline
\end{tabular}

Note: The adjustment factor was calculated as the ratio of the median time between insulin claims divided by the median pharmacy reported days supply for each insulin prescription. If discontinuation or long gap in therapy was observed (gap in refill is $\geq$ days supply of previous fill +90 days) then the claim before the gap was dropped to avoid skewing the data. Please note that this claim was included in the study but not included in the calculation of the adjustment factor. Insulin degludec and rapid acting pen categories included U-100 and U-200 concentrations. The remainder insulins listed in the table are U-100 concentrations unless otherwise noted in the name.

insulin pump during the pre- or post-index periods were also excluded (Appendix, available in online article).

\section{Dose Calculation}

Identification of patients with T2DM initiating a high-dose insulin regimen required calculation of the TDD of all insulin products in the regimen. Dose was calculated using the strength of the medication and the quantity and days supply for each prescription. The various types of insulin are available in varying package sizes, have diverse shelf-lives, and/or are dosed variably by physicians. Additionally, the reported days supply in pharmacy claims does not always reflect these differences. Hence, we first grouped insulins by type, delivery device, and size and then calculated an adjustment factor for each category of insulin to allow for estimating days supply that may be more reflective of the actual length of time that a treatment lasted for a patient (Table 1). ${ }^{22}$ The adjusted days supply was then used to calculate a more realistic estimate of TDD and treatment adherence.

For each insulin category, the adjustment factor was calculated as the ratio of the median time between insulin claims divided by the median pharmacy reported days supply for each insulin prescription for each type of insulin. 
However, if therapy was discontinued, or a long gap in therapy was observed (gap in refill is $>$ [days supply of previous fill +90 days]), then the claim before the gap was excluded from the calculation of the adjustment factor to avoid skewing the data. Table 1 provides the adjustment factors calculated for each of the prespecified insulin categories from $>2$ million insulin claims. An adjusted days supply was calculated for the final study sample by multiplying the actual days supply reported on each pharmacy claim by the corresponding adjustment factor for each insulin category.

The post-index period was divided into 4 quarters, and TDD was calculated for each quarter. To operationalize the calculation of TDD, the relevant time frame was defined by a 91-day moving window. The first 3 quarters were 91 days in length, and the fourth quarter was 92 days. For a claim covering 2 adjacent quarters, the dosage was distributed into both periods according to the number of days in each period. For each patient, we started with the first claim in the identification period and selected all the claims that fell within the 91-day moving window starting from the fill date of the first claim.

TDD was defined as total quantity $(\mathrm{mL})$ dispensed for all insulin claims (regardless of concentration) over the relevant time frame, multiplied by the concentration level (units/mL), and then divided by the sum of adjusted days supply on the relevant claims. Average daily dose (ADD) was defined as total quantity $(\mathrm{mL})$ dispensed for all insulin claims (regardless of concentration) over the relevant time frame, multiplied by the concentration level (units $/ \mathrm{mL}$ ), and then divided by the length of the relevant time frame.

For each claim, the reported days supply was multiplied by the respective adjustment factor. Then, based on the claim dates, the total unique days during the quarter were counted. In order to obtain the TDD, the total quantity of the insulins dispensed during the quarter was converted to total units and divided by the total unique days.

\section{Study Cohorts}

Patients identified for this study were further categorized into treatment groups based on the composition of their index insulin regimens (U-100, U-200, U-300, and U-500R). For the purposes of this study, we did not differentiate between basal and prandial for U-100 or U 200 insulin formulations. In the event that a patient's index regimen included more than 1 of these products, the following criteria were considered for treatment group assignment: (a) If one of the insulins was concentrated ( $>100$ units $/ \mathrm{mL}$ ), the regimen was classified to the corresponding concentrated insulin group; and (b) If a regimen contained more than 1 type of concentrated insulin, it was classified to the highest concentrated insulin group. Based on these criteria, we defined 3 treatment groups or cohorts: (1) Regimen 100 (Reg-100) included patients whose treatment regimen included U-100 but no concentrated insulin and who used TDD>200 units; (2) Regimen 200/300 (Reg-200/300) included patients whose treatment regimen included U-200 and/or U-300 but not U-500R; and (3) Regimen 500 (Reg-500) included patients whose treatment regimen included U-500R. The index regimen was used exclusively to assign patients to their respective treatment cohorts.

\section{Study Measures}

Baseline demographic characteristics including age at index, gender, race/ethnicity, geographic location (Northeast, Midwest, South, and West), and plan type (MAPD, commercial) were evaluated. Among patients enrolled in MAPD, we flagged individuals eligible for Medicare and Medicaid, as well as those eligible for a low-income subsidy (beneficiaries with income below $150 \%$ of poverty and limited resources are eligible for additional premium and cost-share assistance for prescription drugs under the Medicare Part D program). Baseline comorbidity indices, including Deyo Charlson Comorbidity Index (DCCI $)^{23-25}$ and Diabetes Complication and Severity Index (DCSI) ${ }^{25-28}$ were calculated. Presence of prespecified baseline comorbidities (components of DCSI and hypoglycemia), including nephropathy, neuropathy, retinopathy, cardiovascular disease, cerebrovascular disease, peripheral vascular disease, and hypoglycemia based on diagnosis codes in medical claims, were evaluated along with baseline hemoglobin Alc (Alc).

Adherence was measured as the proportion of days covered (PDC) for each regimen in each of the post-index quarters. The estimated level of persistence in each quarter was calculated using the percentage of individuals remaining on index medications for each cohort. Additionally, to understand whether patients were able to adhere to the prescribed high dose needed, we calculated the proportion of patients who maintained TDD $>200$ units during all 4 post-index quarters.

\section{Statistical Analyses}

Descriptive analyses were used to evaluate baseline demographic and clinical characteristics of the cohort by insulin regimen (i.e., Reg-500 and Reg-100). Because of the very small number of patients $(<10)$ identified as treated with Reg-200/300, this cohort was excluded from the analyses. Mean, standard deviations (SD), and medians were reported for continuous variables, while percentages were used to describe categorical variables. The baseline characteristics of patients were compared between cohorts using t-tests or Wilcoxon rank sum tests for continuous variables and chi-square or Fisher exact tests for the categorical variables. Adherence and estimated level of persistence during the post-index 4 quarters were calculated along with the TDD and ADD by cohort. Patients were defined as adherent if PDC was $\geq 80 \%$. 
TABLE 2 Baseline Demographic and Clinical Characteristics of Patients Newly Initiated on High-Dose Insulin (TDD > 200 units)

\section{Characteristics}

Total $=2,339, \mathrm{n}(\%)$

Newly Initiated on High-Dose Insulin Regimen

Demographic Characteristics

\begin{tabular}{|c|c|c|c|c|c|}
\hline Age, years, mean [SD] & 63.4 & {$[9.6]$} & 61.6 & [9.3] & 0.0024 \\
\hline Aged > 65 years, $n(\%)$ & 999 & $(48.4)$ & 111 & $(40.1)$ & 0.0088 \\
\hline \multicolumn{6}{|l|}{ Sex, n (\%) } \\
\hline Male & 1,171 & $(56.8)$ & 146 & $(52.7)$ & 0.1984 \\
\hline Female & 891 & $(43.2)$ & 131 & $(47.3)$ & \\
\hline \multicolumn{6}{|l|}{ Race, n (\%) } \\
\hline White & 1,537 & $(74.5)$ & 200 & $(72.2)$ & 0.4768 \\
\hline Black & 167 & $(8.1)$ & 23 & $(8.3)$ & \\
\hline Other/Unknown & 358 & $(17.4)$ & 54 & $(19.6)$ & \\
\hline \multicolumn{6}{|l|}{ Geographic region, n (\%) } \\
\hline Northeast & 42 & $(2.0)$ & 83 & $(30.0)^{\mathrm{b}}$ & 0.7125 \\
\hline Midwest & 527 & $(25.6)$ & & & \\
\hline South & 1,302 & $(63.1)$ & 165 & $(59.6)$ & \\
\hline West & 191 & (9.3) & 29 & $(10.5)$ & \\
\hline \multicolumn{6}{|l|}{ Plan characteristics, $\mathrm{n}(\%)$} \\
\hline Only low-income subsidy eligible & 324 & $(15.7)$ & 34 & $(12.3)$ & 0.0607 \\
\hline Dual eligibility & \multicolumn{2}{|c|}{$<10^{a}$} & \multicolumn{2}{|c|}{$<10^{\mathrm{b}}$} & \\
\hline Low-income subsidy and dual eligible & 507 & $(24.6)$ & 55 & $(19.9)$ & \\
\hline \multicolumn{6}{|l|}{ Plan type, n (\%) } \\
\hline MAPD & 1,824 & $(88.5)$ & 242 & $(87.4)$ & 0.5947 \\
\hline Commercial & 238 & $(11.5)$ & 35 & $(12.6)$ & \\
\hline \multicolumn{6}{|l|}{ Clinical Characteristics } \\
\hline \multicolumn{6}{|l|}{ Specific comorbidities, n (\%) } \\
\hline Nephropathy & 446 & $(21.6)$ & 87 & $(31.4)$ & 0.0003 \\
\hline Neuropathy & 574 & $(27.8)$ & 86 & $(31.0)$ & 0.2651 \\
\hline Retinopathy & 165 & $(8.0)$ & 31 & $(11.2)$ & 0.0721 \\
\hline Cardiovascular disease & 634 & $(30.7)$ & 91 & $(32.9)$ & 0.4769 \\
\hline Peripheral vascular disease & 260 & $(12.6)$ & 34 & $(12.3)$ & 0.8746 \\
\hline Cerebrovascular disease (TIA, stroke) & 59 & $(2.9)$ & \multicolumn{2}{|c|}{$<10^{\mathrm{b}}$} & 0.3116 \\
\hline Metabolic & \multicolumn{2}{|c|}{$<10^{\mathrm{a}}$} & \multicolumn{2}{|c|}{$<10^{\mathrm{a}}$} & 0.9540 \\
\hline Hypoglycemia & 84 & $(4.1)$ & 14 & $(5.1)$ & 0.4445 \\
\hline Deyo Charlson Comorbidity Index score, mean [SD] & 2.5 & {$[2.1]$} & 2.8 & {$[2.2]$} & 0.0131 \\
\hline Diabetes Complications and Severity Index score, mean [SD] & 1.5 & [1.8] & 1.8 & {$[2.0]$} & 0.0467 \\
\hline \multirow[t]{2}{*}{ Hemoglobin Alc, mean [SD] } & \multicolumn{2}{|c|}{$\mathrm{N}=900$} & \multicolumn{2}{|c|}{$\mathrm{N}=112$} & \\
\hline & 8.6 & [1.7] & 9.2 & {$[1.8]$} & 0.0015 \\
\hline
\end{tabular}

${ }^{a}$ Cell counts less than 10 suppressed due to HIPAA.

${ }^{b}$ Groups merged due to small sample size $(<10)$.

$M A P D=$ Medicare Advantage and Prescription drug plan; $S D=$ standard deviation; TDD = total daily dose; TIA = transient ischemic attack

\section{Results}

We identified 2,339 patients newly initiated on a high-dose insulin regimen of TDD>200 units and assigned them to Reg-100 or Reg-500 cohorts. A greater proportion of patients were on Reg-100 (2,062, 88.2\%) than Reg-500 (277, 11.8\%; Table 2). Patients in the Reg-500 cohort were slightly younger (61.6 [9.3] years) than patients in the Reg-100 cohort (63.4 [9.6] years, $P=0.0024)$. Across both cohorts, over half the patients were men, the majority were white (>70\%), enrolled in MAPD (> 85\%), and lived in the South ( $\geq 60 \%)$.

Among diabetes-related complications evaluated, a higher proportion of patients in the Reg-500 cohort were diagnosed with nephropathy $(31.4 \%$ vs. $21.6 \% ; P=0.0003)$ than in the Reg-100 cohort (Table 3). Patients in the Reg-500 cohort also had higher DCCI (mean [SD] 2.8 [-2.2] vs. $2.5[2.1]$; $P=0.013$ ) and DCSI (1.8 [2.0] vs. 1.5 [1.8]; $P=0.0467)$ comorbidity index 
scores, as well as higher baseline Alc levels (9.2\% [1.8] vs. 8.6\% [1.7]; $P=0.0015)$.

The average adherence to the high-dose insulin regimen during the post-index period, measured as PDC, was 75.5\% (SD 27.0; median 85.2\%) for the Reg-500 cohort and 68.2\% (SD 30.7; median 72.6\%) for the Reg-100 cohort (Table 3). In the Reg-500 and Reg-100 cohorts, $55.2 \%$ and $45.3 \%$ had a $\mathrm{PDC} \geq 80 \%$, respectively. Slightly over half of the patients (51.6\%) in the Reg-500 cohort were newly initiated and maintained insulin TDD $>200$ units during all 4 quarters of the post-index period (Table 3). However, only $23.0 \%$ of patients in the Reg-100 cohort of patients newly initiated on high-dose insulin maintained TDD $>200$ units during the year of the post-index period.

The mean TDD (SD) for the Reg-100 cohort declined from 228.6 (36.0) units during the first quarter to 194.2 (181.4) units during the last quarter (Figure 1). In contrast, the mean TDD (SD) for the Reg-500 cohort increased from 294.2 (102.2) units during the first quarter to 304.8 (281.6) units during the fourth quarter. The mean daily dose (ADD) for the Reg-100 cohort declined from 196.6 (54.8) units in the first quarter to 144.3 (80.3) units in the fourth quarter. In the Reg-500 cohort, the ADD started at a much higher dose of 260.3 (102.9) units and declined to 201.4 (125.8) units in the fourth quarter. The medians for TDD and ADD are reported in Figure 1.

\section{Discussion}

This study evaluated the use of insulins among patients whose insulin doses had been newly titrated up to more than 200 units per day in order to understand baseline characteristics, dosing, adherence, and persistence to therapy. Existing retrospective claims studies related to high-dose insulin in the literature are inclusive of patients with T1DM or T2DM, with the majority of patients diagnosed with T2DM (>80\%), but have not examined these patients separately. ${ }^{18-21}$ Additionally, these studies calculated doses for standard concentration insulin only, ${ }^{19-21}$ whereas this study calculated doses for standard and concentrated insulin formulations. We found that while U-500R insulin has been on the market for more than 20 years, the Reg-500 cohort was much smaller than the Reg-100 cohort. Also, similar to the characteristics of patients reported in a study by Eby et al. (2014), ${ }^{21}$ patients in the Reg-500 cohort were younger than those in the Reg-100 cohort. However, the average age in both cohorts was $>60$ years, which is higher compared with previous studies in the literature. ${ }^{18,20,21}$

While the majority of the population in the current study was enrolled in MAPD, less than half were aged 65 years and older. This could indicate that there was a large population included in the study eligible for Medicare for reasons other than age (e.g., disability). In 2 studies by Eby et al. (2013, 2014) that compared individuals with diabetes using U-500 or U-100 insulin, this pattern was not observed, probably because

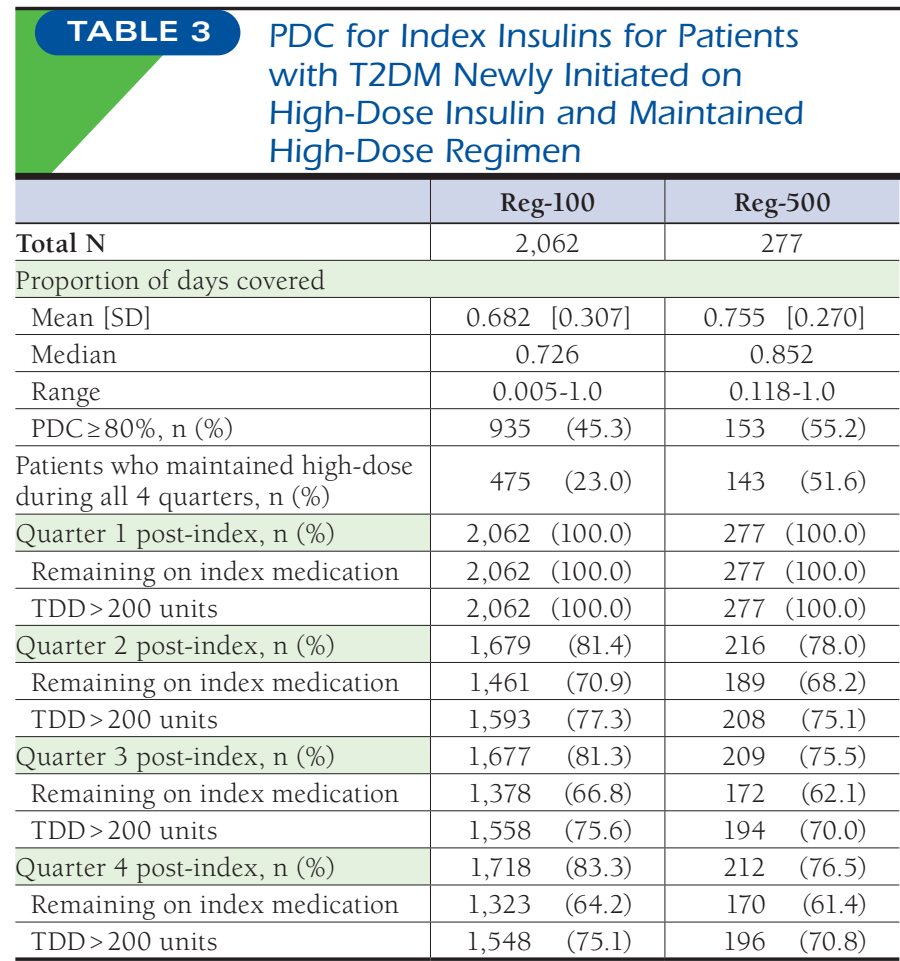

Note: The number of patients with TDD $>200$ units indicate the proportion of patients in that quarter only (90 days). High-dose insulin indicates TDD $>200$ units. $P D C=$ proportion of days covered; $S D=$ standard deviation; $T 2 D M=$ type 2 diabetes mellitus; TDD = total daily dose.

a much smaller portion of the studied patients $(<20 \%)$ were enrolled in Medicare. ${ }^{20,21}$ Additionally, one fifth to one quarter of the patients included in the current study were eligible for Medicare and Medicaid, as well as for a low-income subsidy. Notably, a much higher percentage of patients in the current study lived in the southern states compared with the 2 Eby et al. studies.

Similar to the Eby et al. studies ${ }^{20,21}$ cardiovascular disease was the most prevalent comorbidity followed by neuropathy in this study. The proportion of patients in the Reg-500 cohort with nephropathy was significantly higher than in the Reg-100 cohort. The Reg-500 cohort had higher proportions of patients with cardiovascular, nephropathy, neuropathy, and retinopathy than the Reg-100 cohort. Furthermore, the higher comorbidity index score for the Reg-500 cohort compared with the Reg-100 cohort suggests that the Reg-500 cohort had a higher illness burden than the Reg-100 cohort.

While only half the patients in each cohort had Alc values available at baseline, the Reg-500 cohort had higher Alc values at baseline than the Reg-100 cohort, which might indicate the need for the higher doses of insulin observed in both TDD and ADD in the Reg-500 cohort during each quarter of the post-index period. 


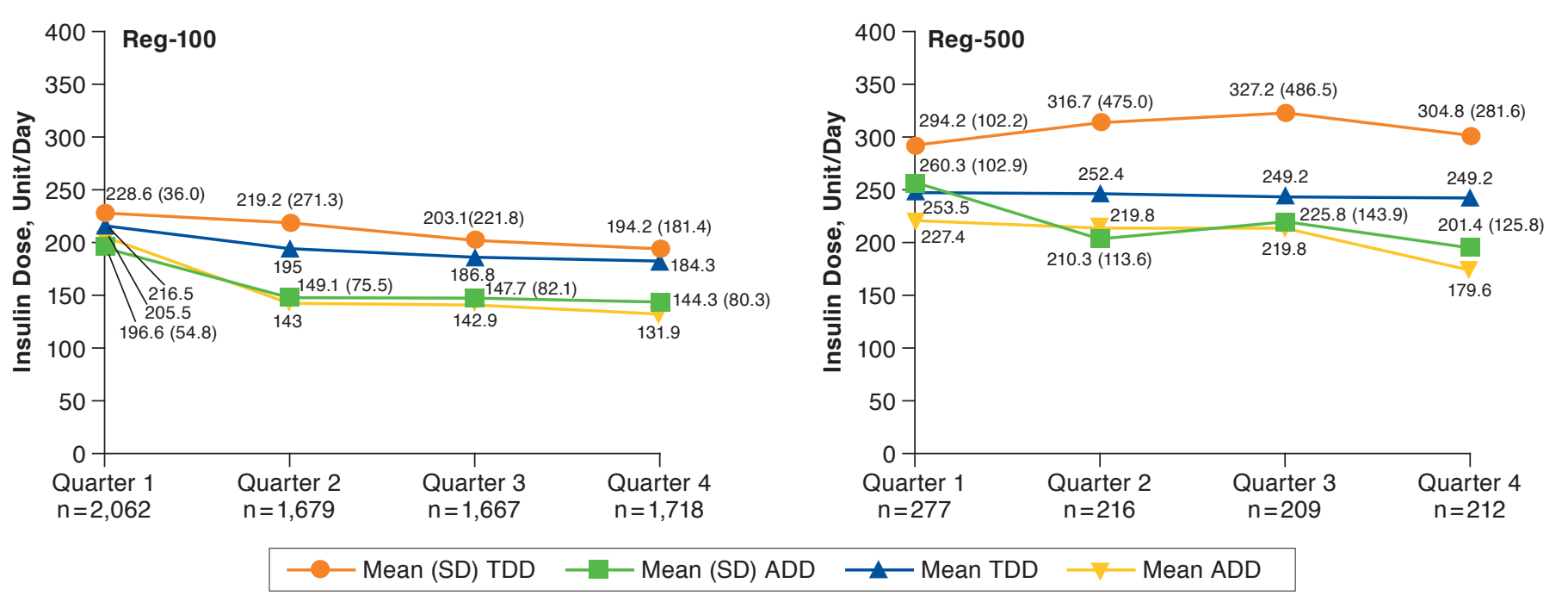

Note: High-dose insulin indicates TDD $>200$ units.

$A D D=$ average daily dose $S D=$ standard deviation; $T D D=$ total daily dose.

Consistent with other studies on insulin persistence, ${ }^{29,30}$ there was a sharp decline in the number of patients in both cohorts continuing on high-dose insulin regimens after the first 3 months of initiation in our study. However, previous studies did not report if there was a change in the daily dose. In our study, TDD in the Reg-100 cohort declined, while TDD in the Reg-500 cohort trended upward initially. The decrease in TDD in the Reg-100 cohort continued after the first quarter but to a lesser degree. The TDD in the Reg-500 cohort increased initially and returned to baseline by the end of the fourth quarter. While it is difficult to ascertain reasons for these changes in dosing patterns from claims data, some potential explanations include changes in insulin needs over time and adherence behavior. Since income could affect adherence behavior, the fact that slightly more patients in the Reg-100 cohort were eligible for low-income subsidies might contribute to the low adherence and the decline in daily dose over time. Additionally, calculating dose using claims data is challenging, given the absence of weight information and non-fixed dosing schedules of insulin, so could be one of reasons for the insulin dose changes.

The average adherence for the Reg-500 and Reg-100 cohorts was higher in our study than in the studies by Eby et al. ${ }^{20,21}$ Over half the patients in the Reg-500 cohort in our study had $\mathrm{PDC} \geq 80 \%$, which is almost double of what was reported by Eby et al. ${ }^{20,21}$ One source of the difference in results could be because the methodology in the previous studies did not adjust the days supply, leading to an underestimation of PDC. In addition, in one of the studies, high-dose was defined as TDD>150 units and may have represented a slightly different population than that in our study. ${ }^{21}$ Another reason for the higher levels of PDC in this study could be that our patients were slightly older than in previous studies, and adherence and persistence tend to be higher among older patients. ${ }^{31,32}$ More importantly, the population in our study were predominantly Medicare beneficiaries. Coverage of glucose-lowering medications by various Medicare Part D plans has been shown to result in improved adherence. ${ }^{33}$

Some of the commonly reported reasons for insulin nonadherence include, but are not limited to, multiple injections, complexity of regimen, challenge of keeping a schedule, and pain associated with injections. ${ }^{3,34,35}$ Additional factors that have been associated with nonadherence include drug cost, younger age, socioeconomic status, and multiple injections. ${ }^{36}$ The fact that less than half of the Reg-100 cohort was adherent might reflect the complexity of the basal-bolus regimen with multiple insulins, the large volume of the injected insulins, and the numerous injections needed. ${ }^{12}$

While there are studies on persistence to insulin therapy in general, these have not evaluated persistence to high-dose insulin therapy. In 2 different studies, Wei et al. (2014, 2017) reported that average persistence to basal insulin therapy over a 1 -year period was $65.0 \%$ and $61.7 \%$ among those newly initiating therapy. ${ }^{31,37}$ For meal-time insulin, Bonafede et al. (2011) reported that $19.1 \%$ were persistent to therapy at 12 months. ${ }^{16}$ With a slightly more relaxed definition of 
persistence, the proportion of patients persistent to therapy with basal/bolus insulin was higher at $42.2 \%{ }^{16}$ In our study, persistence measured as patients remaining on index therapy was similar in both the Reg-500 and Reg-100 cohorts to the persistence reported by Wei et al. However, only half the patients in the Reg-500 cohort and an even lower proportion of patients in the Reg-100 cohort maintained TDD > 200 during the post-index period. While the different methodologies used to define and evaluate persistence in the different studies may explain varying results, patient characteristics and dosing regimen may have also played a role.

While the TDD in the Reg-500 cohort was maintained during the study period, the TDD in the Reg-100 cohort decreased consistently. U-500R insulin, which is recommended to be used as monotherapy and administered twice or three times a day, ${ }^{38,39}$ might have allowed the need for a higher dose of insulin to be better managed and maintained. This is consistent with other studies that have observed patients with chronic illness to be more adherent with less frequently dosed medications. ${ }^{40,41}$ However, insulin needs change over time, and these dose changes may be a reflection of changing insulin requirements for patients to manage their diabetes.

One important observation from all the insulin claims (not just from those who newly initiated high-dose regimens) was that an insulin prescription tended to last longer than the days supply indicated in a claim. This was evident by the fact that the estimated adjustment factors were greater than 1 for all but 1 insulin type. Insulin pen prescriptions seemed to last longer for their patients than insulin vial prescriptions. U-500R vials lasted the longest for their patients among the commonly used insulin vials. Future studies should take this observation into consideration when measuring insulin adherence and persistence.

\section{Limitations}

This study has some limitations to consider. As is typical in retrospective, claims-based research, our findings may have been influenced by potential errors in coding, omissions in claims data, and unmeasured factors such as psychosocial variables. The average dosage estimated based on claims may not necessarily be the dosage that the patients were prescribed or administered. Additionally, lack of medical records makes it difficult to fully understand treatment choices and reasons behind physician decisions. Although the study data were drawn from a large national health plan with persons enrolled throughout the United States, the results may not be generalizable to the overall U.S. population or to specific subpopulations in certain geographic regions. Furthermore, over $85 \%$ of the study sample were MAPD enrollees, hence, the results may not be generalizable because of differences in benefit structures of MAPD versus non-MAPD health plans. Demographics also indicated that the study sample was predominantly white and living in the South, which could further limit the generalizability to the broader population with T2DM on high-dose insulin. Furthermore, 20\%-25\% in each cohort were low-income subsidy and dual eligible.

This study involved calculating insulin dose, which required days supply, quantity in each vial and total quantity supplied. The pharmacy claims data used for this calculation were not always consistent in how information was entered, especially for days supply, given that every patient has a different insulin dose. Additionally, the insulin dose can change each day, adding another layer of complexity in the calculation of TDD. We saw very long gaps in therapy even though insulin was essential for these patients. This suggests that there are issues in dose calculations and therefore in adherence and persistence evaluations, since patients may be purchasing insulin out of pocket and/or receiving samples, which we were unable to evaluate in claims data. Some gaps in claims may be because of hospitalizations, as a result of which adherence may be underestimated.

Administrative claims data does not include details of medication use during the hospital stay, creating artificially prolonged claims gaps. This may have contributed to the decline in ADD but not TDD calculated for the Reg-500 cohort during the post-index period. Lack of inpatient pharmacy data could be a problem in studying patients requiring high-dose insulin, since these patients tend to have more and longer hospitalizations because of the disease state.

Although the adjustment factor calculation in previous studies has been applied to basal insulin only, we used the same method for all insulin, which may or may not have influenced the results. Hypoglycemia remains a treatment concern for patients and providers. While we did measure hypoglycemia at baseline, we did not measure it during the post-index period. Hypoglycemia is a concern for patients needing high-dose insulin and may also be a potential reason for changes in dosing. Currently, there is no consensus on how to measure TDD, adherence, and persistence with insulin treatment, especially with a basal/bolus regimen. We used $\mathrm{PDC} \geq 80 \%$ as a cutoff for adherence. While this is an arbitrary cutoff, it is widely used and accepted in the literature. .2, $^{43}$

Insulin glargine 300 units per mL, insulin lispro 200 units per $\mathrm{mL}$, insulin degludec 200 units per $\mathrm{mL}$, and insulin human injection R U-500 Kwikpen were not widely used during the time period covered in this study, so this study does not include all high-dose insulin regimens available today.

\section{Conclusions}

This study attempted a method of insulin dose calculation using administrative claims data. Despite the limitations and challenges of administrative claims data, we were able to calculate dosing and adherence to high-dose insulin regimens (using standard and concentrated insulin), taking 
into consideration the characteristics of the different kinds of insulin. As with all patients on insulin, it is vital for those prescribed high-dose insulin to maintain their dose for glucose control. Additionally, over time insulin resistance can worsen, which can lead to even higher doses. However, we observed that many patients did not maintain high-dose insulin use over time, especially those on standard U-100 insulin. This dosing pattern appears to reflect the differences in patient characteristics, changing insulin needs, progression of disease, and adherence/persistence behavior of patients on high-dose insulin regimens (Reg-100 and Reg-500).

Maintaining high-dose insulin regimens can be challenging because of the need for a large volume and multiple injections. Since the majority of patients receiving high-dose insulin observed in this study were on an insulin regimen with standard $\mathrm{U}-100$ insulin only, it could be valuable to examine in future studies whether these patients would benefit from a simplified insulin regimen with U-500R as insulin monotherapy in a regimen of 2 or 3 times a day in a real-world setting.

\section{Authors}

JIELING CHEN, PhD; KATELYN BROWN, PharmD, RPh; APRIL DAWN TAYLOR, MSN, CNS, BC-ADM; XUANYAO HE, PhD; and LUDI FAN, PhD, Eli Lilly and Company, Indianapolis, Indiana. RADHIKA NAIR, PhD, and MIR SIADATY, MD, MS, Humana Healthcare Research, Louisville, Kentucky. YUNUS MEAH, PharmD, Humana, Louisville, Kentucky.

AUTHOR CORRESPONDENCE: Jieling Chen, PhD, Eli Lilly and Company, Lilly Corporate Center, Indianapolis, IN 46285.

Tel.: 202.816.2226; E-mail: Chen_jieling@lilly.com.

\section{DISCLOSURES}

This study was supported by funding from Eli Lilly and Company to Humana as a collaborative research project involving employees of both companies. Chen, Brown, Fan, Taylor, and He are employees of Eli Lilly and Company. Nair and Meah are employees of Humana, which received funding to complete this research. Siadaty was an employee of Humana at the time of this study.

\section{ACKNOWLEDGMENTS}

The authors acknowledge Rich Sheer, MS, and Xiaomei Peng, MD, PhD, for their assistance in development of this project and some analysis. The authors also thank Mary Costantino, PhD, for her editorial support.

\section{REFERENCES}

1. Mozaffarian D, Benjamin EJ, Go AS, et al. Heart disease and stroke statistics - 2016 update: a report from the American Heart Association. Circulation. 2016;133(4):e38-360.

2. Centers for Disease Control and Prevention. Nutrition, physical activity, and obesity: data, trends and maps. 2018. Available at: https://www.cdc.gov/ nccdphp/dnpao/data-trends-maps/index.html. Accessed May 27, 2020.
3. Lane WS, Cochran EK, Jackson JA, et al. High-dose insulin therapy: is it time for U-500 insulin? Endocr Pract. 2009;15(1):71-79.

4. Ovalle F. Clinical approach to the patient with diabetes mellitus and very high insulin requirements. Diabetes Res Clin Pract. 2010;90(3):231-42.

5. Dailey AM, Gibert JA, Tannock LR. Durability of glycemic control using U-500 insulin. Diabetes Res Clin Pract. 2012;95(3):340-44.

6. Reutrakul S, Wroblewski K, Brown RL. Clinical use of U-500 regular insulin: review and meta-analysis. J Diabetes Sci Technol. 2012;6(2):412-20.

7. Inzucchi SE, Bergenstal RM, Buse JB, et al. Management of hyperglycaemia in type 2 diabetes: a patient-centered approach. Position statement of the American Diabetes Association (ADA) and the European Association for the Study of Diabetes (EASD). Diabetologia. 2012;55(6):1577-96.

8. Stephens JM, Botteman MF, Hay JW. Economic impact of antidiabetic medications and glycemic control on managed care organizations: a review of the literature. J Manag Care Pharm. 2006;12(2):130-42. Available at: https://www.jmcp.org/doi/10.18553/jmcp.2006.12.2.130.

9. Ho PM, Rumsfeld JS, Masoudi FA, et al. Effect of medication nonadherence on hospitalization and mortality among patients with diabetes mellitus. Arch Intern Med. 2006;166(17):1836-41.

10. Pladevall M, Williams LK, Potts LA, Divine G, Xi H, Lafata JE. Clinical outcomes and adherence to medications measured by claims data in patients with diabetes. Diabetes Care. 2004;27(12):2800-05.

11. Cramer JA, Roy A, Burrell A, et al. Medication compliance and persistence: terminology and definitions. Value Health. 2008;11(1):44-47.

12. Kabul S, Hood RC, Duan R, DeLozier AM, Settles J. Patient-reported outcomes in transition from high-dose U-100 insulin to human regular U-500 insulin in severely insulin-resistant patients with type 2 diabetes: analysis of a randomized clinical trial. Health Qual Life Outcomes. 2016;14(1):139.

13. Hepke KL, Martus MT, Share DA. Costs and utilization associated with pharmaceutical adherence in a diabetic population. Am J Manag Care. 2004;10(2 Pt 2):144-51

14. Sokol MC, McGuigan KA, Verbrugge RR, Epstein RS. Impact of medication adherence on hospitalization risk and healthcare cost. Med Care. 2005;43(6):521-30.

15. Davies MJ, Gagliardino JJ, Gray LJ, Khunti K, Mohan V, Hughes R. Realworld factors affecting adherence to insulin therapy in patients with type 1 or type 2 diabetes mellitus: a systematic review. Diabet Med. 2013;30(5):512-24.

16. Bonafede MM, Kalsekar A, Pawaskar M, et al. Insulin use and persistence in patients with type 2 diabetes adding mealtime insulin to a basal regimen: a retrospective database analysis. BMC Endocr Disord. 2011;11:3.

17. Lee LJ, Li Q, Reynolds MW, Pawaskar MD, Corrigan SM. Comparison of utilization, cost, adherence, and hypoglycemia in patients with type 2 diabetes initiating rapid-acting insulin analog with prefilled pen versus vial/syringe. J Med Econ. 2011;14(1):75-86.

18. Eby EL, Curtis BH, Gelwicks SC, et al. Initiation of human regular U-500 insulin use is associated with improved glycemic control: a realworld U.S. cohort study. BMJ Open Diabetes Res Care. 2015;3(1):e000074.

19. Eby EL, Van Brunt K, Brusko C, Curtis B, Lage MJ. Insulin dosing and outcomes among commercially insured patients with type 2 diabetes in the United States. Clin Ther. 2015;37(10):2297-308.e1.

20. Eby EL, Wang P, Curtis BH, et al. Cost, healthcare resource utilization, and adherence of individuals with diabetes using U-500 or U-100 insulin: a retrospective database analysis. J Med Econ. 2013;16(4):529-38.

21. Eby EL, Zagar AJ, Wang P, et al. Healthcare costs and adherence associated with human regular U-500 versus high-dose U-100 insulin in patients with diabetes. Endocr Pract. 2014;20(7):663-70. 
22. Buysman E, Conner C, Aagren M, Bouchard J, Liu F. Adherence and persistence to a regimen of basal insulin in a pre-filled pen compared to vial/syringe in insulin-naive patients with type 2 diabetes. Curr Med Res Opin. 2011;27(9):1709-17.

23. Quan H, Parsons GA, Ghali WA. Validity of information on comorbidity derived rom ICD-9-CM administrative data. Med Care. 2002;40(8):675-85.

24. Deyo RA, Cherkin DC, Ciol MA. Adapting a clinical comorbidity index for use with ICD-9-CM administrative databases. J Clin Epidemiol. 1992;45(6):613-19.

25. Klabunde C, Potosky A, Legler J, Warren J. Development of a comorbidity index using physician claims data. J Clin Epidemiol. 2000;53(12):1258-67.

26. Chang HY, Weiner JP, Richards TM, Bleich SN, Segal JB. Validating the adapted Diabetes Complications Severity Index in claims data. Am J Manag Care. 2012;18(11):721-26.

27. Glasheen WP, Renda A, Dong Y. Diabetes Complications Severity Index (DCSI) - update and ICD-10 translation. Diabetes Complications. 2017;31(6):1007-13.

28. Young BA, Lin E, Von Korff M, et al. Diabetes Complications Severity Index and risk of mortality, hospitalization, and healthcare utilization. Am J Manag Care. 2008;14(1):15-23.

29. Perez-Nieves M, Kabul S, Desai U, et al. Basal insulin persistence, associated factors, and outcomes after treatment initiation among people with type 2 diabetes mellitus in the U.S. Curr Med Res Opin. 2016;32(4):669-80.

30. Ascher-Svanum H, Lage MJ, Perez-Nieves M, et al. Early discontinuation and restart of insulin in the treatment of type 2 diabetes mellitus. Diabetes Ther. 2014;5(1):225-42.

31. Wei W, Pan C, Xie L, Baser O. Real-world insulin treatment persistence among patients with type 2 diabetes. Endocr Pract. 2014;20(1):52-61.

32. Pickering M, Nsiah I, Nau D, Butterfield K. Validation of a persistence methodology for use in quality measurement [abstract]. J Manag Care Spec Pharm. 2018;24(4a):S42-S43. Available at: https://www.jmcp.org/doi/ pdf/10.18553/jmcp.2018.24.4-a.sl.

33. Capoccia K, Odegard PS, Letassy N. Medication adherence with diabetes medication: a systematic review of the literature. Diabetes Educ. 2016;42(1):34-71.
34. Peyrot M, Barnett AH, Meneghini LF, Schumm-Draeger PM. Insulin adherence behaviours and barriers in the multinational Global Attitudes of Patients and Physicians in Insulin Therapy study. Diabet Med. 2012;29(5):682-89.

35. Cochran EK, Valentine V, Samaan KH, Corey IB, Jackson JA. Practice tips and tools for the successful use of U-500 regular human insulin: the diabetes educator is key. Diabetes Educ. 2014;40(2):153-65.

36. Peyrot M, Rubin RR, Kruger DF, Travis LB. Correlates of insulin injection omission. Diabetes Care. 2010;33(2):240-45.

37. Wei W, Jiang J, Lou Y, Ganguli S, Matusik MS. Benchmarking insulin treatment persistence among patients with type 2 diabetes across different U.S. payer segments. J Manag Care Spec Pharm. 2017;23(3):278-90. Available at: https://www.jmcp.org/doi/10.18553/jmcp.2017.16227.

38. Hood RC, Arakaki RF, Wysham C, Li YG, Settles JA, Jackson JA. Two treatment approaches for human regular U-500 insulin in patients with type 2 diabetes not achieving adequate glycemic control on high dose U-100 insulin therapy with or without oral agents: a randomized, titration-to-target clinical trial Endocr Pract. 2015;21(7):782-93.

39. HUMULIN R U-500 (insulin human injection 500 units) for subcutaneous use. Eli Lilly. Revised November 2019. Available at: https:// pi.lilly.com/us/humulin-r-u500-pi.pdf. Accessed May 27, 2020.

40. Coleman CI, Limone B, Sobieraj DM, et al. Dosing frequency and medication adherence in chronic disease. J Manag Care Pharm. 2012;18(7):527-39. Available at: https://www.jmcp.org/doi/10.18553/ jmcp.2012.18.7.527.

41. Saini SD, Schoenfeld P, Kaulback K, Dubinsky MC. Effect of medication dosing frequency on adherence in chronic diseases. Am J Manag Care. 2009;15(6):e22-33.

42. National Center for Chronic Disease Prevention and Health Promotion, Centers for Disease Control. Calculating proportion of days covered (PDC) for antihypertensive and antidiabetic medications: an evaluation guide for grantees. August 31, 2015. Available at: https://www.cdc.gov/dhdsp/docs/ med-adherence-evaluation-tool.pdf. Accessed May 27, 2020.

43. Karve S, Cleves MA, Helm M, Hudson TJ, West D, Martin BC. Good and poor adherence: optimal cut-point for adherence measures using administrative claims data. Curr Med Res Opin. 2009;25(9):2303-10. 


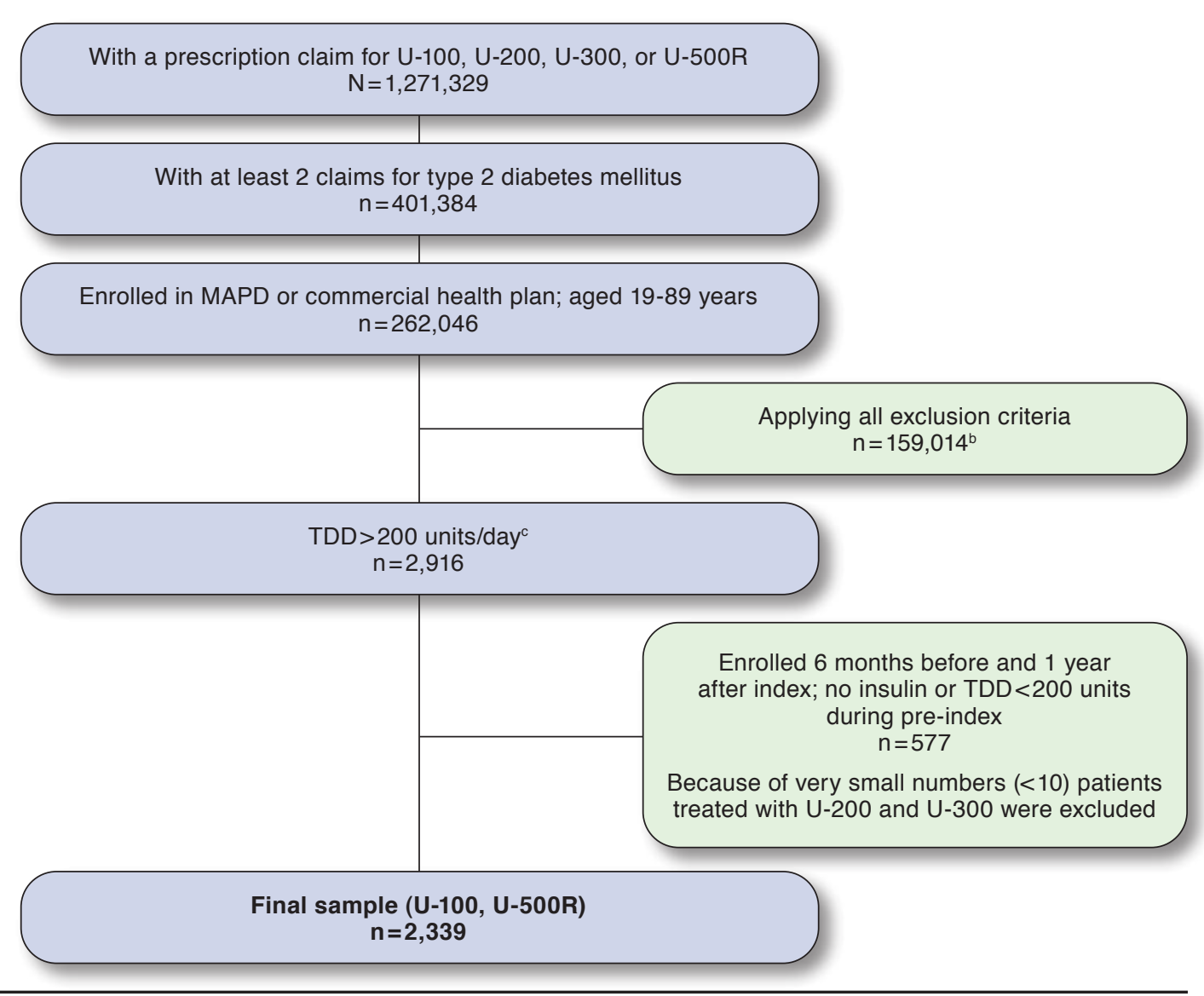

aPatient identification period was between January 2011-August 31, 2015; Only ICD-9-CM codes were used.

${ }^{b}$ Exclusions were diagnosis of secondary diabetes (249.xx), gestational diabetes (648.8x), neonatal diabetes mellitus (775.1), and nonclinical diabetes (790.29) during the pre- or post-index periods, with claims for insulin pumps during the pre- or post-index periods.

cTwo conditions were enforced: (1) TDD > 200 calculated for the entire 91-day window and (2) at least 31 days of TDD $>200$ in the first 61 days of the 91-day window. ICD-9-CM = International Classification of Diseases, Ninth Revision, Clinical Modification; MAPD = Medicare Advantage and Prescription Drug plan; TDD = total daily dose. 